\title{
LA LEY DE INTELIGENCIA COLOMBIANA EN PERSPECTIVA INTERNACIONAL
}

\author{
José Luis González Cussac*
}

\section{Resumen}

El artículo analiza el marco que la Ley 1621 de 2013 fija a las actividades de inteligencia. La regulación de esta materia es bienvenida, pues permite a los ciudadanos conocer cuándo y bajo qué condiciones se pueden restringir sus derechos, al tiempo que reivindica el principio del imperio de la ley, en tanto fija límites a la actuación estatal y a sus servicios de inteligencia. Sin embargo, la ley se ocupa de una actividad especialmente sensible a la cual es connatural el carácter reservado y que puede comprometer de modo serio los derechos de las personas; por ello, es necesario revisar con atención la normatividad aludida para identificar algunos de sus problemas y adelantar posibles soluciones, sin obviar la experiencia -y los desarrollos- en otras latitudes sobre el particular.

\section{Palabras clave}

Ley de Inteligencia, servicios de inteligencia, información reservada, desclasificación de información.

\begin{abstract}
This paper analyses Act 1621 of 2013 that rules the state intelligence activities in Colombia. This regulation is welcome, because it allows citizens to know when and under what conditions it is possible to restrict their civil rights and, at the same time, it reinforces the principle of the rule of law by setting limits to the activity of intelligence services. However, its subject is a confidential activity that might compromise people rights; therefore, it is necessary to carefully review the aforementioned Act to identify some of its -main- problems and offer possible solutions; to do so it will be useful to examine the experiences and regulations of other countries on the same matter.
\end{abstract}

\section{Keywords}

Intelligence activities, intelligence services, confidential information, declassification of information.

* Catedrático de Derecho penal de la Universidad de Valencia, España. Director del Departamento de Derecho Penal de la misma casa de estudios. 


\section{Introducción}

En estas líneas solo dispongo de espacio para trazar algunas de las cuestiones que desde la perspectiva jurídica plantea esta Ley de Inteligencia (Ley 1621 de 2013), pero he de advertir que el reto, aunque modesto, no es en absoluto sencillo. Y no lo es por varias razones: la primera responde, desde luego, al formato del artículo, que al ser reducido impone seleccionar las materias más importantes y afrontarlas además de un modo muy sintético, casi meramente descriptivo, esto es, sin la profundidad que una materia de esta naturaleza requiere.

La segunda dificultad trae causa en lo reciente de la expedición de la ley y, por consiguiente, en la imposibilidad de conocer, con certeza, la eficacia de su aplicación o los problemas prácticos que la misma suscita en la realidad. Por tanto este trabajo transita por el incierto terreno de las hipótesis, es decir, de anticipar ciertos problemas interpretativos que quizás se verifiquen o tal vez no.

La tercera advertencia es consustancial a toda regulación de las actividades de inteligencia, pues, por definición, son secretas. Ello añade serias restricciones a su conocimiento y estudio en cualquier país, como es desde todo punto obvio.

Con todo, a pesar de todas estas cautelas, es posible esbozar algunos comentarios básicos desde la experiencia del derecho comparado, advirtiendo tanto de logros y aciertos como de las posibles carencias o contradicciones o lagunas observadas en esta norma, pero lo más importante quizás es, y sobre todo viniendo de un extranjero, situarla en comparación con las tendencias y modelos existentes en el Derecho comparado e internacional. Naturalmente, se expondrán desde el pertinaz espíritu crítico propio de cualquier trabajo académico, aunque siempre con la intención de colaborar en un mejor servicio al interés general.

En todo caso, la primera valoración ha de ser muy positiva, porque en un Estado de derecho, por definición, todos los poderes públicos y todos los ciudadanos están sometidos al 'imperio de la ley'. Por consiguiente, la más elemental exigencia de seguridad jurídica impone la regulación precisa y pública de cualquier actividad. Y de esta exigencia no escapa nada ni nadie: tampoco los servicios de inteligencia. De modo que la expedición de una ley en la materia contribuye, sin duda, a perfilar las funciones constitucionales asignadas a los departamentos competentes para garantizar la defensa y seguridad nacionales.

De igual forma, resulta vital para que los ciudadanos y el conjunto de la sociedad conozcan cuándo pueden ser restringidos legítimamente sus derechos, pero también para conocer los límites del Estado y sus posibilidades de demanda de protección en caso de abuso. Con otras palabras, una regulación escrita de los servicios de inteligencia afianza su funcionamiento y su visualización por la sociedad como un servicio público legítimo, fiable, eficaz y normalizado. De ahí que una norma de esta naturaleza deba contener el marco constitucional y legal de sus actuaciones, finalidades, objetivos y funciones; su organización y estructura; el régimen y acceso de sus integrantes; los controles externos e internos; y los procedimientos de coordinación y cooperación en el ámbito nacional e internacional. 
Finalmente, una ley de inteligencia permite que los servidores públicos de inteligencia conozcan fielmente sus obligaciones, lo que sin duda contribuye a una mejora indiscutible de la calidad y eficacia de su labor.

En suma, una ley de inteligencia es una herramienta básica, esencial e imprescindible para toda la sociedad democrática, porque establece reglas claras de actuación. Sin reglas nadie sabe a qué atenerse con certeza y esa incertidumbre no es buena para ninguna comunidad. Ni tampoco para su seguridad colectiva e individual.

\section{Tendencias en el derecho comparado e internacional}

Una tendencia fuerte y constante en las últimas décadas empuja hacia la institucionalización de los servicios de inteligencia; esto es, a una reforma de sus leyes o a la creación de nuevos instrumentos normativos más precisos y más transparentes. En términos generales, puede decirse que dicha tendencia se inició en la década de los setenta del pasado siglo en Europa Occidental, EE.UU. o Canadá y, con la caída del Muro de Berlín, se extendió a algunos países de Europa Oriental. Hasta prácticamente los primeros años del siglo XXI dicha orientación no se aprecia con claridad en Iberoamérica, a excepción de Brasil, ya en 1999, pero desde entonces esta dirección también se manifiesta en varios países tales como Argentina y Perú en 2001, Chile en 2004 y Guatemala en 2005.

Indudablemente, a este cambio han contribuido el nuevo escenario geopolítico mundial y regional, la aparición de nuevas amenazas, la revolución tecnológica, la consolidación y el fortalecimiento de los sistemas democráticos, la crisis económica y otros factores comunes o singulares. Todos ellos han impulsado a los Estados a dotarse de regulaciones normativas de las actividades de inteligencia (Ugarte, 2000, pp. $11-17$ y pp. 343 y ss).

Desde la perspectiva interna, destaca la preocupación por establecer mecanismos de controles parlamentarios y gubernamentales efectivos, así como la exigencia de adecuar las actuaciones de inteligencia a los cánones mínimos de respeto a los derechos y garantías fundamentales. Y, desde la perspectiva exterior, superada la tensión de la Guerra Fría, el clima mayor de unas relaciones internacionales más pacíficas ha facilitado el nacimiento de numerosos instrumentos de coordinación y cooperación, o el desarrollo de núcleos de inteligencia en organismos internacionales. Todo lo cual, a su vez, ha requerido un incipiente cuerpo normativo.

En síntesis, puede afirmarse que los servicios y actividades de inteligencia han progresado hacia una normalización jurídica propia del Estado democrático de derecho (Born \& Leigh, 2005, pp. 3-22). El avance se ha logrado con normas escritas que determinan las funciones, finalidades, estructura orgánica, procedimientos de actuación, controles externos e internos, acceso y régimen jurídico de los funcionarios adscritos, coordinación y colaboración entre los diversos departamentos de seguridad, presupuesto y gasto y proceso de clasificación y desclasificación de información (Díaz, 2001, p. 157). Sin lugar a dudas, todo ello ha 
fortalecido la legitimación de las actividades de inteligencia mediante un mejor y mayor recurso al derecho.

\section{Los nuevos retos de las normativas de inteligencia}

En las ciencias sociales, el tiempo y el espacio lo cambian todo, aunque con diferente impacto; más aún en nuestra era, tan extraordinariamente mutable. El derecho y la inteligencia, y su intersección, tampoco escapan a esta máxima, de modo que debemos detenernos en las cuestiones no resueltas todavía o en aquéllas que arrastran dificultades y problemas desde tiempo atrás. Es decir, nuevas y viejas cuestiones que, en ocasiones entrelazadas, obligan a continuar buscando fórmulas normativas que ofrezcan pautas estables de resolución de estos conflictos.

\section{Uso y límites de las nuevas tecnologías.}

Tanto en el plano internacional como en el nacional sobresale una: el uso de las nuevas tecnologías y el impacto que ello comporta para los derechos fundamentales de los ciudadanos, para las empresas y para los Estados. El derecho a la intimidad personal, el secreto económico e industrial de las corporaciones, y la información reservada de los Estados, se ven amenazadas por la intromisión y el espionaje, facilitado por el desarrollo constante de mecanismos e instrumentos tecnológicos. Esta materia ha sufrido un giro radical en los últimos años y ni la comunidad internacional, ni las naciones, han sido capaces de dar respuesta normativa clara y precisa a los límites y controles en la utilización, hoy desmesurada, de estas nuevas herramientas. Es un reto de la mayor transcendencia tanto para el derecho como para la seguridad. Basta recordar la creciente proliferación de términos en este campo: 'ciberamenazas', 'ciberdelitos', 'ciberseguridad', 'ciberguerra', 'ciberespacio', 'ciberterrorismo'.

\section{Reconstruyendo la categoría de seguridad interior.}

Mientras que la noción de 'seguridad exterior', sus amenazas y respuestas, aparecen generalmente bien definidas legalmente, la de 'seguridad interior' sigue mostrando algunas insuficiencias. En cierta forma, puede afirmarse que el interés se ha desplazado singularmente hacia esta última categoría, focalizando el impacto potencial de las actividades de inteligencia sobre la misma. Tres son los puntos centrales de esta inflexión, aunque me concentraré en el tercero, de tal forma que solo enunciaré los dos primeros.

El primero, está referido a la necesidad de desarrollar normas idóneas para regular la gestión de los servicios de inteligencia, o sea, de acercar esta materia a la más amplia y bien construida de las políticas públicas, donde entre otros ejes se trazan estándares de eficiencia, eficacia y control presupuestario (Ugarte, 2005, pp. 47-51).

El segundo, discurre por la necesidad de precisar normativamente las prioridades de los servicios de inteligencia en sus actividades destinadas a preservar la seguridad interior. Así, unos optan porque sea la propia Ley de Inteligencia la que 
contenga y ordene estas prioridades. Por el contrario, otros advierten de la dificultad de hacerlo en una clase de norma tan estable como es una ley y, por ello, abogan por el recurso a su enumeración en otros instrumentos normativos de rango inferior y actualizables regularmente, por ejemplo, a través de planes o directivas anuales de inteligencia; desde luego, existen fórmulas mixtas que combinan ambas técnicas normativas.

Tampoco hay que desconocer la posible confusión de niveles o conceptos, pues desde una consideración teórica básica se debe diferenciar lo que son las funciones generales (propias de describirse en una ley), de lo que es la concreción y jerarquización de las actividades. Esta última es la referencia más próxima a la noción de 'prioridades', inevitablemente cambiantes y, por lo tanto, necesariamente objeto de regulación en normas igualmente modificables. Por consiguiente, una correcta técnica legislativa debe recurrir a normas con rango inferior a la ley, de naturaleza más flexible, y de mayores facilidad y rapidez de modificación.

Conviene aquí recordar la complejidad y diversidad de 'agendas nacionales de seguridad', incluso en la misma región. La mutación de las amenazas o la aparición de algunas nuevas, arroja luz a la decisión de optar en este ámbito por reglas flexibles y adaptables y, en todo caso, subrayar que los objetivos estratégicos corresponde fijarlos al poder ejecutivo, quien a su vez es el destinatario final de la inteligencia (Sanz, 2012).

El tercero, en el cual me detendré, está vinculado a la categoría de la seguridad interior y que no es otro que el ascenso de la llamada inteligencia criminal o inteligencia policial (Ugarte, 2012). Esta progresión no debería extrañar a nadie, pues es obvia la concurrencia de diferentes agencias estatales de seguridad en materias comunes como terrorismo, crimen organizado (drogas, armas, personas, lavado de activos, corrupción), protección del orden constitucional, extremismo y radicalismo ideológico, 'ciberseguridad', protección de recursos ambientales, etc. Sin embargo, fusionar las palabras 'inteligencia', 'policía' o 'crimen' es más sencillo que comprender todo su complejo significado y consecuencias; en realidad, ello esconde sutiles -aunque fundamentales- cuestiones que afectan a los pilares básicos de la arquitectura jurídica del modelo de seguridad y justicia de un Estado.

En realidad, es clave definir y construir con claridad y precisión el sistema en el que las diferentes agencias de seguridad y defensa deben tener unas competencias, funciones y controles definidos. Desde luego, deben establecerse protocolos de coordinación y cooperación, pero siempre partiendo de la autonomía funcional de cada uno. Históricamente, todos sabemos de unidades de inteligencia militar que mantienen cada vez más un perfil técnico y circunscrito a sus funciones constitucionales, por lo general orientadas a la seguridad exterior; por consiguiente, salvo escasas excepciones, el problema de delimitación se produce entre las agencias de inteligencia civil y las policiales.

A mi juicio, la distinción es fundamental, porque si el lenguaje sirve para algo, en este caso ha de expresar diferentes funciones constitucionales y que, en tanto 
diferentes, conllevan regímenes jurídicos diversos. Con mayor claridad puede decirse que en el seno de modelos constitucionales propios de un Estado democrático de derecho, es posible la coexistencia de servicios de inteligencia con funciones diferentes a las atribuidas a los servicios policiales. En particular, está muy extendido configurar organismos encargados de elaborar inteligencia estratégica y sin ninguna competencia policial; por su parte, la finalidad capital de la policía es prevenir y perseguir delitos. La distinción aparece crucial, porque, entonces, la diferencia entre la inteligencia practicada por unos y otros es sustancial (González, 2011, pp. 267-294).

De veras, ambas inteligencias poseen aquél punto de encuentro de materias comunes que genéricamente pudiera referirse al objetivo de la prevención de delitos, pero, desde luego, los servicios de inteligencia estratégica jamás tienen -en este modelo- la misión de perseguir delitos. Aquí es donde reside la clave de bóveda: las agencias de inteligencia estratégica no persiguen delitos ni tampoco su misión es acopiar pruebas incriminatorias [Estévez (2005) cita la doctrina alemana de Trennungsgebot]. Por eso mismo, es posible e incluso conveniente que unos y otros estén sometidos a diferentes grados de control judicial, normas de obtención de pruebas y de sometimiento estricto al principio de legalidad.

Las diferencias se aprecian más claramente si, junto a la noción de 'inteligencia criminal', añadimos las de investigación criminal o delictiva y de 'actuación policial orientada por inteligencia' (Intelligence-led policing).

La inteligencia criminal debe estar orientada a prevenir delitos, neutralizando amenazas serias, graves, probables e inminentes contra bienes jurídicos esenciales en el correspondiente ordenamiento jurídico. Técnicamente, su tiempo de actuación es en fase de preparación del delito. Incluso, puede que los actos realizados no sean todavía punibles legalmente -actos preparatorios impunes-; en este sentido, puede emplearse, en ocasiones, como un recurso extrapenal de las políticas de seguridad. Ahora bien, aunque disponga de un cierto margen de discrecionalidad, siempre deberá actuar bajo control judicial, singularmente en casos de utilización de medios susceptibles de intromisión en los derechos fundamentales -intimidad-. Tampoco es sencillo definir el procedimiento y validez de incorporación como prueba al proceso penal de las informaciones obtenidas.

Por su parte, la investigación criminal es un concepto sólidamente construido en una centenaria tradición jurídica en la que sobresalen las pautas de actuación contenidas en las leyes penales sustantivas y procesales, así como en las normas policiales y conocimientos de criminalística y policía científica y forense. Es competencia de los cuerpos policiales y está destinada a la represión y persecución de hechos delictivos, con estricto sometimiento al principio de legalidad, pleno control judicial y finalidad de adquisición de pruebas. En síntesis, se trata de una actividad de inteligencia sumamente reglada y formalizada (González, 2012, pp. 287-289). 
Más recientemente, se ha ido acuñando la llamada 'actuación policial orientada por inteligencia'. Con este título se quiere designar el uso de la inteligencia como herramienta para la toma de decisiones orientadas a la reducción de delitos y a su prevención.

El auge de la inteligencia criminal y de otras categorías asociadas, además de su interés intrínseco, aporta un ángulo excelente para apreciar un cambio sustancial de tendencia en las actividades de inteligencia: la popularidad del modelo de policía comunitaria y de las actuaciones policiales orientadas por inteligencia, ha abierto el debate sobre su idoneidad para exportarlo a las clásicas agencias de inteligencia militares o civiles. En este contexto se habla del tránsito del modelo de la 'seguridad nacional' al de la 'seguridad pública'; de la integración de dimensiones humanas, locales, nacionales e internacionales en la noción de seguridad -perspectiva antropocéntrica-; y traslación desde la seguridad exterior a la nueva noción de seguridad interior del criterio de 'todos ganan cuando uno gana' -no suma cero-.

Sin embargo, el pretendido tránsito desde la seguridad nacional a la seguridad pública comporta, también, importantes modificaciones del régimen jurídico. Este último, como se acaba de exponer, procede esencialmente de la actuación y funciones policiales, que ya vimos, vienen determinadas por un estricto control de legalidad, supervisión judicial y recursos probatorios. Por lo tanto, con la fusión de los conceptos de seguridad se está también equiparando el régimen jurídico de todas las agencias de seguridad e inteligencia.

En mi opinión, la tendencia hacia un sometimiento pleno al derecho de todas las agencias de seguridad e inteligencia es innegable. Ahora bien, sometimiento no significa necesariamente igualdad completa e idéntica en el canon de legalidad ni del grado de supervisión y control judicial. Por supuesto, cuanto mayores son los controles, la trasparencia y la confrontación de informaciones, aumentan el interés y aprobación social hacia las instituciones y sus actividades, y se reducen las posibilidades de abuso, impunidad y de lesión de los derechos fundamentales.

El reto consiste en establecer reglas que permitan un mayor nivel de rendición de cuentas y supervisión de los servicios de inteligencia sin que ello comprometa nuestra seguridad. De ahí que es menester explorar fórmulas creativas que permitan establecer procedimientos de control judicial sin riesgo de exponer métodos, fuentes y personas.

En todo caso, esta corriente alcanza tanto la mencionada necesidad de control presupuestario y de eficacia -gestión de políticas públicas-, como al de legalidad o adecuación de sus actividades, dentro o fuera de su territorio, al respeto a los derechos y garantías fundamentales. Hasta ahora, la gran autonomía de las agencias de inteligencia se había podido mantener merced a las expectativas sociales de éxito en la neutralización de amenazas vinculadas a la categoría de seguridad nacional que, para muchos, conlleva cierto grado de eficacia extralegal. Sin duda el fenómeno del terrorismo es un buen ejemplo de esto último, como también de las dificultades de mantener -en la actualidad-la tradicional y rígida separación entre 
seguridad exterior y seguridad interior. Pero, justamente, el terrorismo es definido en la mayoría de legislaciones nacionales e internacionales como un delito común, esto es, no político y, en consecuencia, debe ser perseguido y reprimido como tal (González, 2016, pp. 115-135).

Dejando ahora de lado los ricos matices de esta dinámica, la tendencia hacia la democratización de la idea de seguridad significa indudablemente un nítido tránsito desde el 'Estado de seguridad' a un 'Estado de derecho', con defensa de los principios democráticos (Swenson, 2009). Estos avances exigen nuevas normas sobre estructuras, funciones y controles en la práctica de las actividades de inteligencia. Hoy no se discute tanto sobre su legitimidad, sino más bien sobre un nuevo enfoque de la tensión entre secreto y publicidad. El grado de transparencia, autonomía, visibilidad y penetración de los servicios en la sociedad avanza en la dirección apuntada de un mayor sometimiento al derecho y a un incremento de su neutralidad en las decisiones de la política interior.

Por último, señalar que la evolución de la inteligencia desde una inteligencia militar hacia una 'inteligencia ampliada' conlleva la necesidad de compartir estas funciones entre diversas agencias de distinta naturaleza. Esta tendencia es innegable y satisfactoria, aunque deben prevenirse los riesgos de una militarización de la policía, o de una policialización de las fuerzas armadas y de los servicios de inteligencia estratégica (Swenson, s.f.).

\section{Información compartida.}

Otra esfera de alta complejidad es la relativa a la regulación del manejo de la denominada 'información compartida'.

Recientemente, algunos académicos norteamericanos han llamado la atención sobre la nula formalización y supervisión de la información intercambiada en las redes internacionales de inteligencia (Swenson, s.f.). La escasa formalización comienza en la misma toma de los acuerdos, procedimientos y uso de esta clase de información compartida, pues ello corresponde a las agencias de inteligencia con total autonomía. Es más, en numerosos supuestos ni siquiera responden a un protocolo institucionalizado entre las agencias, sino que nace, se desarrolla y finaliza en el compromiso individual de los agentes y oficiales a título personal.

Las exigencias de mutua confianza y de protección de métodos y de fuentes han permitido levantar un 'ambiente libre de restricciones' que se traduce en excepciones hasta en los procedimientos de desclasificación y en una falta significativa de control tanto desde el derecho interno como desde el derecho internacional. Las dificultades y excepcionalidad del principio de aplicación ultraterritorial de la ley, y la limitada jurisdicción de los tribunales internacionales, incluida la Corte Penal Internacional, favorecen la creación de espacios opacos, fuera de cualquier control jurídico y de alto riesgo para los derechos fundamentales. 
De particular interés es el régimen de las acciones encubiertas -clandestinas o negables- fuera de las fronteras de un determinado país: aquí se aprecia con claridad la casi absoluta falta de reglas aplicables y de supervisión de estas actividades, porque para el derecho interno del país del servicio que las ejecuta puede oponerse el principio de aplicación territorial de la ley penal. A ello se suman las limitaciones de la jurisdicción internacional penal. Y por último, en el país donde se realizan, puede existir desconocimiento, falta de medios para perseguirlas eficazmente o connivencia interesada con las mismas.

Por ejemplo, los servicios exteriores del Estado A solicitan a la policía o los servicios del país $B$ que detengan u obtengan información dentro de su territorio de personas nacionales o extranjeras para luego intercambiarla. $\mathrm{O}$ a la inversa, las agencias de seguridad del Estado $Z$ requieren a los servicios extranjeros del país $Y$ para que obtengan informaciones que ellos no pueden obtener lícitamente en su territorio conforme a su legislación. En definitiva, quid pro quo y absoluta falta de transparencia y control jurídico en este oscuro ámbito.

Estas prácticas deben ser reconducidas a los criterios generales, esto es, al sometimiento al derecho, y no es suficiente el recurso a reglas éticas internas de los propios servicios. Desde luego, existen muchas fórmulas jurídicas que concilien la necesidad de mantenimiento de la mutua confianza y del secreto de métodos y fuentes con las exigencias de control y adecuación a los derechos fundamentales.

En resumen, este ámbito constituye una de las últimas fronteras de opacidad de los servicios de inteligencia, y por consiguiente requiere reconciliar el secreto de Estado y las actividades de inteligencia con la sociedad de un Estado de derecho, mediante el recurso a reglas jurídicas.

\section{Conclusión.}

Podemos concluir advirtiendo de una continua evolución desde una inteligencia en origen militar (preparación de guerras y defensa nacional), que transitó después por un entendimiento de la seguridad interior condicionado por el escenario de la Guerra Fría y con notable autonomía de actuación de las agencias de inteligencia; hasta aproximarse, actualmente, a una fórmula que algunos identifican como 'inteligencia pública' que demanda y exige un control permanente.

\section{Observaciones críticas a la Ley de Inteligencia colombiana}

Tras este sintético repaso a las tendencias y retos que en esta materia se observan en clave comparada e internacional, estamos en mejores condiciones para efectuar una valoración de la Ley de Inteligencia Colombiana que, recuérdese, fue objeto de control constitucional previo mediante la Sentencia C-540 de 2012.

La primera idea fuerte ya ha sido anunciada: solo por el hecho cierto de estar hablando de una Ley de Inteligencia ya debemos emitir un juicio positivo. En este sentido verificamos que también Colombia camina en la misma dirección que el resto de países democráticos, es decir, hacia regulaciones escritas de las actividades 
de inteligencia. Esto es, discurre en la normalización de la actividad de inteligencia como parte de las políticas públicas y con pleno sometimiento al derecho.

En el caso colombiano, el trámite se sujetó a lo previsto para las leyes estatutarias -bastante más exigente, desde el punto de vista formal, que el previsto para las leyes ordinarias-, lo cual se corresponde con la relación entre la temática desarrollada en la Ley de Inteligencia y los derechos fundamentales. La pertinencia del trámite aludido fue explicada por la Corte Constitucional colombiana en los siguientes términos:

Esta Sala encuentra que el contenido del proyecto de ley revisado que concierne al
desarrollo de actividades de inteligencia y contrainteligencia, envuelve indubitable-
mente regulaciones que comprometen elementos estructurales y básicos de los de-
rechos fundamentales como la intimidad, el habeas data, el buen nombre, el acceso
a la información, el debido proceso y el principio de legalidad, lo cual explica que
su aprobación se cumpla bajo la reserva de ley estatutaria (art. 152, lit. a) superior).
Puede afirmarse que las disposiciones del proyecto de ley estatutaria sistematizan
dentro de un cuerpo legal materias que atañen y resultan próximas al contenido
esencial de los derechos fundamentales. Imponen limitaciones a su ejercicio y regu-
lan aspectos principalísimos de estos derechos. Además, sus preceptos en principio
buscan estatuir un sistema normativo integral (C- 540 de 2012, pp. 96-97).

En segundo término recordar dos frases muy conocidas que -creo- expresan muy claramente algo que todos compartimos y debemos tener presente. Comienzo con aquella que reza: 'la práctica de inteligencia es la última expresión de una identidad y soberanía nacional'. Y, añado, la que asegura que una de las mejores formas de conocer la cultura y la identidad de un país es estudiar las prácticas de sus servicios de inteligencia. En efecto, una ley de inteligencia, como una ley electoral o una ley penal, regulan materias tan esenciales para la convivencia de un pueblo que necesariamente expresan sus valores más profundos. De suerte que la mirada de un extranjero a cualquiera de estos cuerpos legislativos le permite comprender y conocer mucho mejor la cultura íntima de ese país.

Así pues esta ley -como cualquier otra- es hija de un contexto histórico determinado y fuera de él no puede interpretarse. Este contexto, en cuanto a la Ley de Inteligencia se refiere, viene marcado de forma particularmente decisiva por dos factores claves: primero, el largo conflicto armado y la presencia de poderosas organizaciones criminales; $y$, segundo, el tratamiento judicial, mediático y político de algunos casos de persecución de los fenómenos descritos.

Sin embargo, en mi opinión, resulta igualmente significativa la disolución del Departamento Administrativo de Seguridad (DAS), puesto que este dato confirma una máxima advertida por todos los estudiosos de la materia: todo asunto de inteligencia que se judicializa no solo se convierte en lo que los juristas llamamos un 'caso difícil', sino también en un escándalo político, en el que los servicios secretos, irónicamente, se convierten, a su pesar, en el centro diario del escrutinio de la opinión pública (González, 2012, pp.141-160). Cuando esto ocurre siempre cambia algo: no solo personas, sino también instituciones, y nacen leyes nuevas o 
reformas de las anteriores. Se trata de ofrecer a la sociedad una solución a los abusos o errores, o al menos, una apariencia de solución. Pero el mayor riesgo, a juicio de los especialistas, es entonces abrazar una tipología de cultura de inteligencia, caracterizada por empezar desde 'el año cero'.

Igualmente se acredita que las 'agendas de seguridad' son muy complejas de perfilar y menos de reducir a parámetros comunes. Esto es claro en una perspectiva internacional, pero también sucede en el ámbito regional; el ejemplo del área de América Latina lo confirma, pues la diversidad geográfica, geopolítica, económica y social exige matices entre los diversos países a la hora de diseñar sus respectivas agendas de seguridad.

Ciertamente, todos los países de este área comparten factores: fin de la época de Guerra Fría, terminación o avance hacia el final de guerras civiles y conflictos internos, reducción del uso de la violencia institucional, concurrencia hacia la formalización e institucionalización o, en fin, disminución de conflictos interestatales y camino decidido hacia la cooperación (MERCOSUR; CARICOM, Comunidad Andina de Naciones). De suerte que hoy los riesgos son sustancialmente distintos de los anteriores, o cuanto menos, han surgido nuevas amenazas. Entre ellas, destacar las relativas a la seguridad económica y energética, las vulnerabilidades sociales (pobreza extrema, exclusión y marginalidad), las medioambientales, los desastres naturales y las pandemias o la ciberseguridad (Rodríguez, s.f.).

No es menos cierto que en algunos países subsisten viejos riesgos y en ocasiones estos han mutado. En particular la aparición o permanencia de agentes no estatales hostiles y la fragilidad institucional. Una enumeración sucinta es suficiente para enmarcar el análisis: terrorismo, crimen organizado (tráfico de drogas, armas, personas, violencia, corrupción), el denominado narcoterrorismo, y bandas criminales juveniles. La seguridad de las fronteras y la inmigración desordenada constituyen también problemas muy graves. Por el contrario, se confirma un bajo riesgo de conflictos armados entre Estados (Rodríguez, s.f. y Organización de los Estados Americanos, 2003).

Así, pues, estos cambios han condicionado inevitablemente la paulatina transformación de las agendas de seguridad del área de Iberoamérica. Singular mención merece el tránsito hacia concepciones más amplias y antropocéntricas de la seguridad, que superan el tradicional entendimiento de la seguridad nacional/ estatal. Y sobre todo, que evitan errores del pasado que identificaban la seguridad nacional con los intereses de un gobierno, de un grupo o partido, o aún peor, de personas concretas. En resumen, se constata una evolución hacia la 'inteligencia pública' y una auténtica cultura de inteligencia nacional.

Como advierten Swenson y Lemory (2009), la inteligencia estratégica solo puede encontrar espacios y un desarrollo adecuado en aquéllos países que posean un proyecto e intereses nacionales definidos con claridad y compartidos en un amplio consenso. En verdad existen diversas tipologías de culturas nacionales de inteligencia, pero la globalización obliga a una delicada combinación de valores 
con un realismo pragmático. Los mitos, las utopías y el idealismo sin ponderación conducen inexorablemente hacia el fracaso.

El conjunto de coordenadas descritas debiera estar presente en la ley de Inteligencia de Colombia. De otro modo, nacería ya como un texto anacrónico, lastrado por el pasado y por consiguiente limitado para dar respuestas eficaces al presente.

El art. 2 se limita a definir solo las funciones de inteligencia y la contrainteligencia. Es justamente a partir de aquí que llama la atención la ausencia de referencia a las 'acciones encubiertas o clandestinas', esto es, a la posibilidad de utilizar y poseer medios y actividades bajo cobertura. En esta línea, aunque se regula el uso de identidades diferentes de los agentes de inteligencia (arts. 40 y 41), me parece parca la norma al no hacer referencia explícita a esta técnica extendida a vehículos y otra clase de certificados personales o económicos.

En el art. 3 se señalan las agencias competentes mediante una técnica mixta de numerus clausus y numerus apertus. Es decir, primero se enumeran con precisión y detalle las dependencias de las Fuerzas Militares y la Policía Nacional organizadas por estas para tal fin, la Unidad de Información y Análisis Financiero (UIAF), pero, a continuación se abre a 'los demás organismos que faculte para ello la ley'. Es obvio que falta una referencia expresa en esta ley, o en otra, a la Dirección Nacional de Inteligencia.

El art 4, referido a los límites y fines de la función de inteligencia y contrainteligencia, resulta interesante, porque la mayoría de sistemas legales hacen referencia exclusivamente al sometimiento a la Constitución y al resto del ordenamiento jurídico nacional o interno, pero no incluyen, como lo hace la regulación colombiana, una referencia expresa y sin matices al Derecho Internacional Humanitario ni al Derecho Internacional de los Derechos Humanos. Esta inclusión puede resultar problemática, porque si los Tratados y Convenios Internacionales ya están suscritos y ratificados por la República de Colombia, ya se han incorporado y forman parte del ordenamiento interno. Y si no lo están, su referencia en este precepto, abre la posibilidad de aplicación a actividades de inteligencia desplegadas en territorio colombiano 'más allá y por encima del derecho nacional' y a instancia tanto de personas físicas y jurídicas nacionales como extranjeras. Por ello, cabe preguntarse si tal consagración supone una renuncia -gratuita- de soberanía.

Lo relativo al art. 5, referido a los principios, suscita una primera duda en cuanto a si una interpretación literal obligaría a una verificación y justificación detallada de la actividad y fines, conforme al art. 4, en cada operación concreta.

Tampoco parece conveniente la exigencia de verificación de necesidad, sencillamente porque no todas las actividades de inteligencia comportan un impacto en los derechos fundamentales, ¿por qué habría que elegir otros procedimientos menos gravosos si los electos no restringen ni limitan derechos de los ciudadanos? Hay que recordar que, según todos los estudios existentes, más del $90 \%$ de la información obtenida por los servicios de inteligencia procede de fuentes abiertas que, por definición, no suponen limitación alguna de derechos de los ciudadanos. 
Por último, este precepto no distingue adecuadamente los cánones de idoneidad, necesidad y proporcionalidad. Conforme a doctrina constitucional muy extendida, un estándar es la adecuación a fines legítimos y constitucionales (legitimidad del fin perseguido), otro se refiere a la necesidad en abstracto de adoptar medidas restrictivas de derechos (no hay otro medio posible y está justificado el sacrificio) y, finalmente, el canon de proporcionalidad en sentido estricto o del caso concreto, que examina si los medios empleados son exagerados para el objetivo.

El Capítulo III (arts. 10 a 13), relativo a la coordinación y la cooperación de las agencias de inteligencia y contrainteligencia, contiene, más bien una declaración de intenciones que un auténtico procedimiento.

La reunión de la Junta de Inteligencia Conjunta (JIC) se establece mensualmente ('al menos una vez al mes'), lo que no es común en el derecho comparado que generalmente la fija con carácter semanal. En cuanto a su composición, echo de menos la presencia de los máximos responsables de los ministerios de relaciones exteriores, economía e interior. Tampoco se define qué representante actúa como secretario ni la coordinación de la comunidad nacional de inteligencia.

En cuanto al control y la supervisión (arts. 14 a 27 del Capítulo IV), puede advertirse que, en las autorizaciones de las operaciones, surge de nuevo la problemática remisión al Derecho Internacional Humanitario y al Derecho Internacional de los Derechos Humanos, no solo en punto de las autorizaciones (art. 15), sino, también, en el diseño y/o adecuación de los manuales de inteligencia y contrainteligencia (art. 16).

Muy debatido en el espacio europeo es el monitoreo o captación de los datos de tráfico en las comunicaciones cerradas, y si deben estar sometidos a una autorización judicial previa o basta un control judicial posterior. Tampoco es sencilla la regulación sobre las compañías de comunicaciones acerca de la obligación de almacenamiento y custodia de estos datos y del contenido. El art. 17 parece considerarlo legal en cualquier caso, a condición de que sean 'debidamente' incorporadas dentro de órdenes de operaciones o misiones de trabajo.

Naturalmente, es siempre polémico el régimen de la interceptación de las comunicaciones cerradas. Sabido es que muchos países no requieren la autorización judicial previa o que otros, aunque si la requieren, no se lleva a cabo en el marco de un proceso penal sino por jueces ad hoc dentro de un procedimiento especial y secreto, por ejemplo, en España.

Cabe preguntarse si, a la luz de la fórmula legal empleada, se equipara -jurídicamente- a todos los servicios de inteligencia con la policía y, consiguientemente, se restringe la interceptación de las comunicaciones a la averiguación de delitos. En caso de una respuesta afirmativa, se cerraría el paso a la elaboración de inteligencia estratégica que requiera de interceptaciones, la cual es de singular importancia dentro de la seguridad económica, pues las restricciones impuestas a los servicios de inteligencia colombianos les restaría competitividad 
frente a los de otros países, incluso dentro del territorio nacional. Esto limitaría extraordinariamente las funciones de contrainteligencia en una materia que, amén de ser hoy una de las prioridades en todas las agendas de seguridad nacional, no siempre incurre en actividades delictivas; basta poner el ejemplo de acciones de influencia a través de lobbys.

En mi opinión, el tenor del art. 15 de la Constitución Política permite un régimen jurídico de las interceptaciones de las comunicaciones semejante al de otros países democráticos, en los que se equilibra la protección del derecho fundamental a la intimidad y las funciones de inteligencia y contrainteligencia estratégica, por definición no vinculadas necesariamente a la práctica de conductas delictivas.

Es aquí donde es menester comenzar por recordar la diferencia básica en las competencias, funciones y finalidades de los servicios de inteligencia, en relación a las desempeñadas -conforme a la Constitución y al resto del ordenamiento jurídico-por los servicios policiales.

Como se ha expuesto en los anteriores apartados, la diferente finalidad perseguida por agencias de inteligencia y policiales, deviene determinante en la comprensión y calificación del problema. En efecto, pues la intromisión en la intimidad practicada por los servicios policiales se inscribe necesariamente en el marco de un proceso penal y está orientada al acopio de evidencias destinadas a la represión de hechos delictivos; de ahí que se exija su práctica conforme a unas estrictas garantías. Sin embargo, la intromisión en la intimidad provocada en el desarrollo de las actividades de los servicios de inteligencia -aun cuando comporten el mismo grado de afectación al contenido del derecho fundamental-, nunca persiguen obtener pruebas susceptibles de trasladarse a un proceso penal, sino exclusivamente obtener información para, después de analizarla, finalmente difundirla al decisor político, dentro de las finalidades relativas a la seguridad nacional. Se trata de intervenciones de naturaleza extraprocesal, preventiva y prospectiva.

Del mismo modo, no parece gozar de un fundamento sólido la afirmación de que 'solo es apto para restringir el derecho a la intimidad el procedimiento criminal', algo así como negar la consideración de procedimiento judicial a otros procedimientos formalizados, incluidos los ad hoc o especiales.

De otra parte, añadir argumentos de derecho comparado, en la medida que se trata de modelos constitucionales similares. Esto es claro en el espacio europeo, que bajo la armonización de la jurisprudencia del Tribunal Europeo de Derechos Humanos, se aplican regímenes menos exigentes formalmente que el descrito en la presente ley. Así, en relación al modelo alemán, que no contiene control judicial alguno, la significativa Sentencia del TEDH, Klass vs Alemania, 1978.

En otro orden de cosas, nada se dice en la ley acerca del uso de artificios de grabación de la imagen y sonido en espacios públicos ni en cerrados, ni tampoco de la posibilidad de entrada en domicilios. 
Por su parte, los procedimientos establecidos de control parlamentario (arts. 19 y ss.) distan en algunos puntos de las prácticas más extendidas en el derecho comparado. Ciertamente, es común en los sistemas democráticos el acceso a las informaciones reservadas de las cámaras legislativas o de comisiones ad hoc para así cumplir con sus funciones de control. Sin embargo, esta supervisión parlamentaria generalmente presenta algunas excepciones: las relativas a fuentes, medios e identidades; $y$ las informaciones procedentes de servicios extranjeros $u$ organizaciones internacionales. Algunas legislaciones también conceden al máximo representante del Estado la facultad de vetar la entrega de informaciones clasificadas al órgano parlamentario competente, si considera que con ello se pone en riesgo la seguridad nacional. Y, adicionalmente, muchas leyes de inteligencia incluyen expresamente la obligación de devolver las informaciones reservadas, pues el control solo llega a acceder, pero nunca a retener.

Por lo que se refiere al Capítulo V, 'Bases de datos y archivos' (arts. 28 a 32), puede decirse que la apropiada tutela de la llamada 'intimidad informática' es una constante en todos los ordenamientos jurídicos democráticos. Empero, igualmente, los archivos de datos de los servicios de inteligencia suelen tener un régimen jurídico especial y esto último no se encuentra claramente contenido en la Ley de Inteligencia.

La Ley de Inteligencia también incluye una regulación de la materia comúnmente denominada 'secretos oficiales' y que generalmente integra un cuerpo legal diferente (Capítulo VI. Reserva de la información, arts. 33 a 39). Con carácter general, establece un plazo legal de reserva de 30 años y, excepcionalmente, el Presidente de la República puede extender otros 15 años adicionales la reserva a petición de alguno de los organismos competentes y siempre que concurra alguna de las causas enumeradas en el art. 33. A propósito de la posibilidad de ampliar la reserva, el Proyecto original disponía que la reserva se pudiera ampliar ilimitadamente hasta que se comprobara la 'desmovilización del grupo armado al margen de la ley'; no obstante, tal disposición fue declarada inexequible.

Hasta acá, la ley acoge una técnica legal de clasificación vinculada a la naturaleza de las funciones desempeñadas por los organismos de inteligencia y contrainteligencia; por consiguiente, toda actividad de inteligencia y contrainteligencia está legalmente declarada secreta por 30 años. La excepción introduce un criterio de clasificación 'por el acto', en este caso otorgado exclusivamente al Presidente de la República.

Sin embargo, a partir de aquí, con la lectura de los cuatro parágrafos siguientes, el modelo legal sufre excepciones: así, en el parágrafo $1^{\circ}$, nuevamente el Presidente de la República posee la potestad de desclasificar la información antes de los 30 años si no pone en riesgo la seguridad nacional.

En el segundo parágrafo comienzan las dudas, pues los responsables de los organismos de inteligencia tienen la obligación de motivar por escrito la razonabilidad y proporcionalidad para acogerse a la reserva. Esta disposición es algo 
desconcertante, pues si la reserva está declarada legalmente, el directivo de inteligencia no debería tener que razonarlo, sino simplemente invocar que la ley lo ha declarado secreto y, por lo tanto, que él está obligado a mantener la reserva.

El Parágrafo $3^{\circ}$ tampoco está exento de interrogantes. En primer lugar, se refiere a 'cualquier' servidor público, sea o no integrante de un organismo de inteligencia. Pero respecto a estos últimos el problema es mayor porque obliga a poner en conocimiento de las autoridades administrativas, penales, o disciplinarias competentes, 'la recolección ilegal de información', sin que ello comporte vulnerar el deber de reserva. Sin embargo, la ley no aclara el parámetro de medición de la ilegalidad suficiente para que el funcionario de inteligencia quede exonerado de su obligación de guardar secreto. Es decir, no se imponen criterios objetivos de medición de la ilegalidad, lo que significa equiparar meras irregularidades con graves violaciones constitucionales o criterios subjetivos de ilegalidad con manifiestas e indiscutibles infracciones legales.

El Parágrafo $4^{\circ}$ resulta desconcertante en la medida que, si es la ley la que determina que una materia está reservada, todos los ciudadanos quedan sujetos a esta obligación. Y cuando digo todos incluyo no solo a los servidores públicos de inteligencia, sino a las autoridades políticas, judiciales y por supuesto a todos los ciudadanos, incluidos los periodistas. Todavía resulta menos coincidente con el derecho comparado que se obligue, esto es, se garantice a los periodistas el derecho-deber de guardar el secreto de sus fuentes. Una lectura conjunta y sistemática de este precepto explicita que el secreto de Estado no alcanza a todos los ciudadanos y sin embargo el secreto sobre las fuentes de los periodistas sí es absoluto.

Por su parte, el art. 34, atinente a la 'inoponibilidad de la reserva', dispone que los secretos oficiales no son oponibles a las autoridades judiciales, fiscales y disciplinarias cuando lo requieran en el ejercicio de sus atribuciones, salvo que comprometan la seguridad nacional o ponga en peligro la integridad de personas, agentes y fuentes. Esta declaración incurre en una doble contradicción lógica: primero, porque la reserva está declarada por la propia ley, de modo que exclusivamente el procedimiento establecido en la ley o la autoridad competente, que solo es el Presidente de la República, puede decretar la desclasificación; de otro modo se produciría un conflicto de competencias o incluso la usurpación de funciones. Y, segundo, porque por definición toda actividad de inteligencia y contrainteligencia está orientada a la seguridad nacional.

Respecto al valor probatorio de los informes de inteligencia (art. 35) las dudas son igualmente notorias. En efecto, si el art. 17 limita la interceptación de comunicaciones cerradas solo a las autorizadas judicialmente dentro de un proceso penal, resulta extraño que las evidencias allí conocidas no puedan ser utilizadas como prueba. De otra parte, su exclusión probatoria parece desconocer la posibilidad de informes de inteligencia a título de documental o de peritaje de expertos, algo asumido en la mayoría de ordenamientos. Cuestión distinta es que la información de inteligencia pueda utilizarse directamente en un proceso penal. 
De nuevo el art. 39, atinente a las excepciones a los deberes de denuncia y declaración, no aporta criterios objetivos de valoración con los que determinar los casos en los que el servidor de inteligencia puede denunciar y aquéllos otros en los que solo se apoyan en su valoración subjetiva la infracción de la ley o la comisión de delitos graves. Otra vez hay que insistir en que si la clasificación de la información viene impuesta por la ley, nadie puede disponer de la misma arbitrariamente.

Es importante destacar que la sección -única- dedicada a las reformas que debían introducirse a la legislación penal y militar, para garantizar la reserva legal de la información de inteligencia y contrainteligencia, fue declara inexequible. Al hilo de ello, conviene precisar que la declaratoria se fundó en vicios de forma, por la vulneración del principio de 'unidad de materia',

toda vez que si bien el título alude a modificaciones que conciernen a la "reserva legal de la información de inteligencia y contrainteligencia", las conductas y competencias reguladas terminan reformando disposiciones penales que no solo tocan con dicho eje temático, sino en general con el manejo de información reservada a cargo de cualquier servidor público, que también compromete la normatividad penal militar, por lo que el legislador excedió la materia objeto de regulación y rompió todo vínculo de conexidad con el contenido y alcance del presente proyecto de ley. De todas maneras, la Corte exhortará al Congreso para que dentro del margen de configuración legislativa en materia de política criminal, configure tipos penales concretos o causales de agravación específicas destinadas a salvaguardar de manera concreta la reserva de la información de inteligencia y contrainteligencia (C- 540 de 2012).

Tales modificaciones (creación de tipos penales concretos o de causales de agravación específicas), por cierto, no se han producido.

Finalmente, debe advertirse que la Ley de Inteligencia presta escasa atención al régimen económico y presupuestario, al estatuto personal de los agentes de inteligencia y al desarrollo orgánico de los servicios. Los mencionados son temas, huelga decirlo, de gran relevancia para el correcto funcionamiento de las actividades reguladas en la misma.

\section{Referencias}

Aranda, E. (2004). El marco constitucional de los servicios de inteligencia. En D. Navarro y M. Esteban (Coords.), Gestión del conocimiento y servicios de inteligencia (155-180). Madrid: Boletin Oficial del Estado.

Berki, R. (1986). Security and Society. Reflections on Law, Order and Politics. London: J. M. Dent \& Sons Limited.

Best, R. (2001). Intelligence and Law Enforcement: Countering Transnational Threats to the U.S. CRS Report for Congress (Order Code RL30252).

Birkinshaw, P. (1990). Reforming the secret state. Philadelphia: Open University Press. 
Born, H. \& Leigh, I. (2005). Making Intelligence Accountable: Legal Standards and Best Practice for Oversight of Intelligence Agencies. Oslo: House of the Parliament of Norway.

Cavero, M. (1996). La Ley 11/1995 de 11 de mayo, reguladora de la utilización y control de los créditos destinados a gastos reservados. La Ley, (25), 1280-1285.

Cerone, J. (2007). Jurisdiction and Power: The Intersection of Human Rights Law \& the Law of Non-International Armed Conflict in an Extraterritorial Context. Israel Law Review, 40 (2), 72-128.

Chiavario, M. (Coord.). (1978). Segreto di Stato e giustizia penale. Bolonia: Zanichelli.

Clarke, D.L. (1984). Secrecy, foreign intelligence and civil liberties: has the pendulum swung too far? Political Science Quarterly, 99 (3), 493-120.

Consejo de Europa. (2010). Seguridad vs Democracia. Los controles democráticos en las Fuerzas Armadas y Servicios de Seguridad. Pamplona: Laocoonte.

De Lucas, F. (1990). Democracia y transparencia. Sobre poder, secreto y publicidad. Anuario de Filosofía del Derecho, (7), 131-146.

Díaz, A. (2001). La función de los servicios de inteligencia. En C. de Cueto y J. Jordán (Coords.), Introducción a los estudios de seguridad y defensa (p. 155-174). Granada: Comares.

Díaz, A. (Dir) (2013). Diccionario LID Inteligencia y seguridad. Madrid: LID.

Díaz, A. (Dir) (2016) Conceptos fundamentales de inteligencia. Valencia: Tirant lo Blanch.

Diez-Picazo, L. (1996). El secreto de Estado en el proceso penal. A propósito de la Sentencia del Tribunal de Conflictos de Jurisdicción de 14 de diciembre de 1994. La Ley, (1), 1564-1566.

Diez-Picazo, L. (1997). Publicidad y secreto en la Constitución. Ejemplar dedicado a El acceso judicial a la obtención de datos. Cuadernos de Derecho Judicial, (25), 43-62.

Esteban, M. (Coord). (2007). Glosario de inteligencia. Madrid: Ministerio de Defensa.

Estévez, E. (2005). La actividad de inteligencia en nuevos contextos normativos democráticos. Adaptando la inteligencia realizada en el ámbito interior. Seminario Internacional "A Atividade de Inteligéncia e os desafíos contemporáneos". Agência Brasileira de Inteligência, Brasília DF.

Fernández, J. (1999). Los secretos de Estado en España. Jurisprudencia y teoría constitucional (I). La Ley, (4762), 1796-1811. 
Fernández, J. (1999). Los secretos de Estado en España. Jurisprudencia y teoría constitucional (II), La Ley, (4762).

Ferrajoli, L. (1974). Segreto e informazione nello Stato contemporaneo. Democrazia e Diritto, 14, 721-728.

Gómez-Reino, E. (1976). El principio de publicidad de la acción del Estado y la técnica de los secretos oficiales. Revista Española de Derecho Administrativo, (8), 115-136.

González, J. (2010). Nuevas amenazas a la seguridad nacional: los desafíos del nuevo terrorismo. Revista Internacional Derecho Penal Contemporáneo, (32), 81-107.

González, J. (2011). Intromisión en la intimidad y servicios de inteligencia. En Un Derecho penal comprometido. Libro Homenaje al Profesor Dr. Gerardo Landrove Díaz (pp. 267-294). Valencia: Tirant lo Blanch.

González, J. (2012). El secreto de Estado en el proceso penal: entre la denegación de auxilio y el delito de revelación. Inteligencia y seguridad: Revista de Análisis y prospectiva, (12), 141-160.

González, J. (2016). Servicios de inteligencia y contraterrorismo. En G. Portilla y A. Pérez (Dirs.), El terrorismo en la actualidad: un nuevo enfoque político-criminal (pp. 115-135). Universidad de Salamanca: Ratio Legis.

González, J. y Larriba, B. (2010). Un Nuevo Enfoque Legal de la Inteligencia Competitiva. Inteligencia y seguridad: Revista de Análisis y prospectiva, (8), 39-73.

González, J. y Larriba, B. (2011). Inteligencia Económica y Competitiva: Estrategias legales en las nuevas agendas de Seguridad Nacional. Valencia: Tirant lo Blanch

González, J. y Larriba, B. y Fernández, A. (2012). Derecho. En J. González (Coord.), Inteligencia. Valencia: Tirant lo Blanch.

Guarnieri, C. y Pederzoli P. (1997). La Democrazia Giudiziaria. Bolonia: Il Mulino.

Halperin, M. \& Hoffman, D. (1977). Top secret: national security and the right to know. Washington: New Republic Books.

Hoffman, D. (1981). Governmental secrecy and the founding fathers. A study in constitutional controls. Westport, Connecticut: Greenwood.

Hoffman, D. (1985). The right to Know. Oakland, Calif.: Data Center.

Hooper, D. (1987). Official secrets: the use and abuse of the act. Londres: Secker \& Warburg Ltd.

Klass vs Alemania. (1978, septiembre 6). Tribunal Europeo de Derechos Humanos.

Larriba, B. (2009). Crítica al empleo de interrogatorios y tortura para producir inteligencia frente al terrorismo. Revista General de Derecho Penal, (12). 
Ley 1621 de 2013. Por medio de la cual se expiden normas para fortalecer el Marco Jurídico que permite a los organismos que llevan a cabo actividades de inteligencia y contrainteligencia cumplir con su misión constitucional y legal, y se dictan otras disposiciones. Diario Oficial No. 48.764. Congreso de la República de Colombia, abril de 2013.

MacCormick, N. (1986). The Interest of the State and the Rule of Law. En P. Wallington \& R. Merkin (Eds.), Essays in Memory of Professor F.H. Lawson, Londres: Butterworths.

McCuen, E. (1990). Secret democracy: civil liberties vs. the national security state. Hudson, Wis., G.E. McCuen Publications.

Morales, O. (1996). Fondos reservados, revelación de secretos y denegación de auxilio. A propósito de los últimos pronunciamientos del Tribunal Supremo. Actualidad Penal, (16), 429-475.

Office of Counterintelligence (DXC) Defense CI \& Humint Center, Defense Intelligence Agency (2011). Terms and Definitions of Interest for DoD Counterintelligence Professional. Glossary, U.S.

Organización de los Estados Americanos - [OEA]. (2003). Declaración sobre seguridad en las Américas. México.

Ortega, M. (2011). Siguiendo el conflicto: hechos y análisis. Pensando en una mejor inteligencia para Colombia (Documento No. 59) Fundación Ideas para la Paz.

Otero, P. (2000). La revelación de secreto de Estado en los procedimientos penales. Valencia: Tirant.

Orts, E. (1994). Revelación y uso indebido de secretos e informaciones. Cuadernos de Derecho Judicial, (4), 211-236.

Presidencia de la República (2003). Política de Defensa y Seguridad democrática. Colombia: Ministerio de Defensa Nacional. Recuperado de http://www.oas. org/csh/spanish/documentos/Colombia.pdf

Presidencia de la República. (2011). Política Integral de Seguridad y Defensa para la prosperidad. Colombia: Ministerio de Defensa Nacional. Recuperado de http:/ / www.ceedcds.org.ar/Srd-LibBL/COL/POL_INT_SEG_DEF.pdf

Pérez, M. (2002). Derechos Fundamentales y Servicios de Inteligencia. Un estudio a la luz de la nueva legislación. Granada: Grupo Editorial Universitario.

Pooley, J., \& Halligan, R. (2000). Intelligence and the Law. En J. Miller (Ed.), Millenium Intelligence: Understanding and Conducting Competitive Intelligence in the Digital Age (pp.171-187), CyberAge Books, Medford, NJ.

Quintero, G. (1980). El delito de desobediencia y la desobediencia justificada. Cuadernos de Politica Criminal, (12), 59-82. 
Quintero, G. (1989). La colaboración entre poderes y la denegación de auxilio. Poder Judicial, (8, especial Seguridad ciudadana), 23-40.

Rebollo, R. (1996). La revelación de secretos e informaciones por funcionario público. Barcelona: Cedecs.

Revenga, M. (1996). El control del secreto de Estado. Reflexiones (preliminares) de Derecho comparado. Jueces para la Democracia, (25), 20-25.

Revenga, M. (1997). Razonamiento judicial, seguridad nacional y secreto de Estado. Cuadernos de Derecho Judicial, (25, ejemplar dedicado a: Acceso judicial a la obtención de datos), 17-42.

Rodríguez, G. (2007). Antiguas y nuevas amenazas a la seguridad de América Latina. Casede. Recuperado de la base de datos de www.tesis.proyectos.com.

Romeo, C. (2004). Los delitos de descubrimiento y revelación de secretos. Valencia: Tirant lo Blanch.

Ruiz, C. (2007). Problemas actuales del Derecho de los servicios de inteligencia. Inteligencia y Seguridad: Revista de análisis y prospectiva, (2), 13-46.

Ruiz, C. (2002). Servicios de inteligencia y seguridad del Estado constitucional. Madrid: Tecnos.

Sanz, F. (2012). Opinión e Inteligencia (Documento No. 45). Reino Unido de España: Instituto Español de Estudios Estratégicos.

Salas, L. (2008). Sistema judicial, secreto económico y secreto de Estado. Inteligencia y Seguridad: Revista de análisis y prospectiva, (5), 91-122.

Segrelles de Arenaza, I. (1994). Protección penal del Secreto de Estado. Madrid: Edersa.

Segrelles De Arenaza, I. (1997). El secreto de Estado ilegal: aspectos básicos. Cuadernos de Politica Criminal, (62), 415-433.

Sentencia C-540 (2012, julio 12). Demanda de Inconstitucionalidad. M.P. Jorge Iván Palacio Palacio. Corte Constitucional.

Swenson, R. (s.f.). Reflexiones sobre inteligencia: la autonomía de decisión, la rendición democrática de cuentas y los fundamentos para la supervisión. (Trad. B. Hughes y F. Torres). Artículo inédito para Insyde. México: Insyde A.C.

Swenson, R. \& Lemozy, S. (Coords.) (2009). Democratización de la función de inteligencia. Washington D.C.: National Defense Intelligence College.

Szott, G. (2009). The problematic role of criminal law in regulating use of information: The case of the Economic Espionage Act. Public Law and Legal Theory Research Paper Series, 2009-A-5. 
Ugarte, J. (2005). La relación entre inteligencia y política, y sus consecuencias en las estructuras y normas de los Sistemas de Inteligencia. Brasilia. Recuperado de https: / / fas.org/irp/ world/argentina/ugarte.pdf

Ugarte, J. (2000). Legislación de inteligencia: Legitimidad y Eficacia. Oficinaen Washington para asuntos latinoamericanos. Ciudad de Guatemala: WOLA \& SEDEM. Recuperado de http://www.sedem.org.gt/publicaciones/electronicas/ legislacion.pdf

Ugarte, J. (2012). Hacia una doctrina de inteligencia criminal. Cuadernos de Seguridad, (15), 79-112. Recuperado de http://www.minseg.gob.ar/sites/default/files/ Publicaciones/Cuadernos_Seguridad_15.pdf

Varela, L. (1991). ¿Secreto de Estado o secreto contra el Estado? (a propósito de la sentencia publicada en el caso "Amedo", ¿o quizá debiera ser otra la etiqueta?...). Jueces para la democracia, (13), 62-65.

Vervaele, J. (2008). Terrorismo e intercambio de información entre los servicios de inteligencia y las autoridades de investigación judicial en los Estados Unidos y en los Países Bajos: ¿Derecho penal de emergencia? En J. Gómez (Coord.), Prueba y proceso penal (pp. 421-463), Valencia: Tirant lo Blanch.

Wilkinson, H. (2007). Secretos de Estado y Estado de Derecho: régimen jurídico de los secretos oficiales en España. Barcelona: Atelier. 